\title{
Vocal cord and pharyngeal distal myopathy
}

INSERM

\section{Source}

INSERM. (1999). Orphanet: an online rare disease and orphan drug data base. Vocal cord and pharyngeal distal myopathy. ORPHA:600

Vocal cord and pharyngeal distal myopathy (VCPDM) is a rare autosomal dominant distal myopathy characterized by adult onset of muscle weakness in the feet and hands (slowly progressing to involve proximal limb muscles) combined with vocal or swallowing dysfunction and frequent respiratory muscle involvement in later stages. Normal to mildly elevated creatine kinase (CK) serum levels and rimmed-vacuolated dystrophic muscle fiber changes are associated laboratory and pathologic findings. 